\title{
EXTRAÇÃO DE SOLO EXPOSTO E INFERÊNCIA DO TIPO DE SOLO A PARTIR DO ESTUDO DA DRENAGEM USANDO-SE TÉCNICAS DE SENSORIAMENTO REMOTO E GEOPROCESSAMENTO
}

\author{
Jedman Dantas Motta ${ }^{1}$, Ana Lúcia Bezerra Candeias² e Eduardo da Nóbrega Gonzaga ${ }^{1}$
}

\begin{abstract}
RESUMO
Este trabalho procura obter uma região de solo exposto a partir da observação do atributo cor e inferir sobre determinado tipo de solo a partir de um mapa de drenagem obtido através de imagens temáticas TM-Landsat (banda 5 e composições coloridas 7R/2G/1B, 7R/5G/2B e 5R/4G/3B) georefenciadas. A região considerada localiza-se próximo à cidade de Campina Grande, Estado da Paraíba, onde existem poucos trabalhos utilizando produlos Landsat, e quase nenhum trabalho cartográlico, devido à grande concentração de nuvens durante todo o ano, o que dificulta a obtenção dos dados por meio aéreo ou espacial.
\end{abstract}

Palavras-chave: sensoriamento remoto, processamento de imagens, SGI, drenagem

\section{EXTRACTION OF EXPOSED SOIL AND INFERENCES OF TYPE OF SOIL THROUGH DRAINAGE STUDY USING TECHNIQUES OF REMOTE SENSING AND GEOPROCESSING}

\begin{abstract}
This paper intends to obtain a exposed soil region by color attribute observation and infers over determined type of soil through the drainage map obtained by means of thematic images TM-Landsat (band 5 and color composition 7R/2G/1B, 7R/5G/2B and 5R/4G/3B) georeferenced. The region considered is located near Campina Grande town in Paraíba state where only few have been conducted using Landsat products because the high percentage of cloud during the year.
\end{abstract}

Key words: remote sensing, image processing, GIS, drainage

\section{INTRODUÇÃO}

Este trabalho possui, como área-teste, uma região próximo a Campina Grande, PB, e utiliza imagens Landsat TM órbita-ponto 214-65, com data de passagem de 10.07.1989; tem como objetivos gerar uma imagem temática a partir da observação do atributo cor, gerar um mapa de drenagem a partir da imagem georeferenciada e a inferí-la sobre o tipo de solo a partir do mapa de drenagem.
A área de estudo situa-se ao noroeste do município de Campina Grande, mais precisamente entre os pontos de latitude sul 7'00'00' e $7^{\circ} 30^{\prime} 00^{\prime \prime}$ e os pontos de longitude oeste $36^{\circ} 04^{\prime} 00^{\prime \prime}$ e 35'30'00'; abrange os municípios de Pocinhos, Puxinanã, Lagoa Seca, Alagoa Nova, Areal e Esperança; está localizada entre duas regiões fisiográficas: Brejo e Borborema Oriental; destaca-se na imagem pelo alto grau de reflectância caracterizando uma área de solo exposto. No encontro dessas duas regiōes, há o confronto entre o clima quente e úmido

\footnotetext{
${ }^{1}$ Aluno da (iraduação DEAg - Departamento de Engenharia Agrícola. Titulação: Eng. Agrícola; Inst: DEAg/UFPb; Universidade Federal da Paraíba, Av. Aprígio Veloso 882, Bodocongó, 58109-970, Campina Grande, PB, Brasil.

${ }^{2}$ Professor Adjunto; Inst: DECart/UFPE; End. Postal: DECart/UFPe - Universidade Federal de Pernambuco Av. Prol. Morais Rego 1235.
} CEP 50670-901, Cidade Universitária Recife, PE, Brasil. 
litorâneo e o semi-árido, que favorece a agricultura; o relevo é acidentado e imerso numa grande quantidade de morros, serras e cristas constituídas de terrenos cristalinos pré-Cambrianos. A região apresenta taxa de radiação de energia anual de aproximadamente 3.000 horas de insolação com temperatura anual média de $26^{\circ} \mathrm{C}$. Segundo o projeto RADAM Brasil, a área apresenta distribuição anual de água superconcentrada $(<3$ meses), sua classe de potencial hídrico de superfície é fraca e muito fraca $(<200 \mathrm{~mm}$ com volume de água disponível menor que $200.000 \mathrm{~m}^{3} / \mathrm{km}^{2}$ ao ano).

Dois problemas observados neste trabalho foram:

1. grande cobertura de nuvens sobre a região de interesse nas horas de passagem do satélite;

2. falta de mapas semidetalhados da região, dificultando o georeferenciamento e a coleta de dados.

O primeiro problema foi contornado utilizando-se a imagem de 10.07.1989, que continha baixa cobertura de nuvens na área de interesse; o segundo foi resolvido utilizando-se a carta topográlica da região de Sapé, escala 1/100.000, adjacente à região desejada e, com isto, possibilitou-se o georeferenciamento imagem/mapa.

\section{MATERIAL E MÉTODOS}

O sensor utilizado é o Landsat TM, que opera em sete faixas do espectro eletromagnético. Neste trabalho foram utilizadas a banda 5 e as composições coloridas $7 \mathrm{R} /$ $2 \mathrm{G} / 1 \mathrm{~B}, 7 \mathrm{R} / 5 \mathrm{G} / 2 \mathrm{~B}$ e $5 \mathrm{R} / 4 \mathrm{G} / 3 \mathrm{~B}$ para obtenção do padrão de drenagem. Para o registro, tratamento e georeferenciamento das imagens foi utilizado o soltware SITIM, desenvolvido pelo INPE (Instituto Nacional de Pesquisas Espaciais) que possibilita, dentre muitas aplicações, se realçar determinadas feições ou características de uma área, mascaradas ou influenciadas por áreas adjacentes. Maiores detalhes sobre o sensor, ver em:

http://www.eurimage.it/Products/LS/Mspectral-Chars.html http://www.dpi.inpe.br/html/landsat.html

\section{RESULTADOS E DISCUSSÃO}

\section{Necessidade de realce}

Observando-se as imagens originais (Figuras 1 e 2), nota-se que é necessário realçá-las para ser mais fácil a análise visual, pois devido à atenuação atmosférica, as imagens apresentam-se distorcidas. Existem vários tipos de realce; aqui, escolheu-se o realce por tabela, alterandose o histograma da imagem obtendo melhor distribuição dos níveis de cinza (Figuras 3 e 4 ).

\section{Composição colorida}

As imagens multiespectrais possuem a vantagem de possibilitar diversos tipos de composição colorida, o que depende diretamente da quantidades de bandas do sensor e dos objetos que se deseja extrair. Na Figura 5 são mostradas três composições coloridas da região de interesse, cada uma delas evidenciando melhor certos alvos.

\section{Aplicação do processamento de imagens}

O processamento de imagens pode ser aplicado para diversos fins. No caso estudado, tem-se a classificação pelo atributo cor para determinar solo exposto. Este estudo foi baseado em Sousa (1996) e com ele pretende-se observar a viabilidade desta classificação.

A transformação IHS gera componentes mais próximos à visão humana. Nesta transformação, atribui-se a um pixel uma intensidade (I), uma matiz (H) e uma saturação $(\mathrm{S})$.
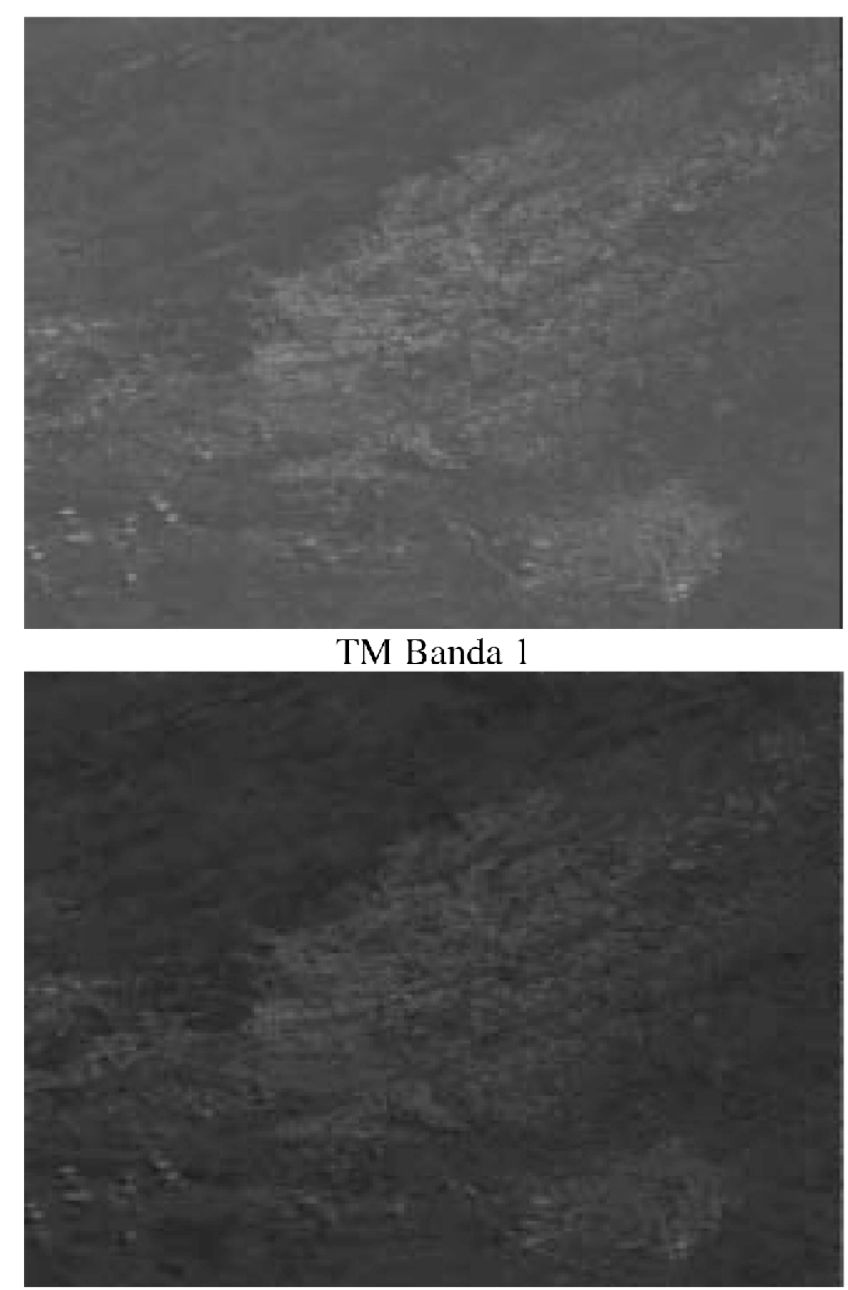

TM Banda 2

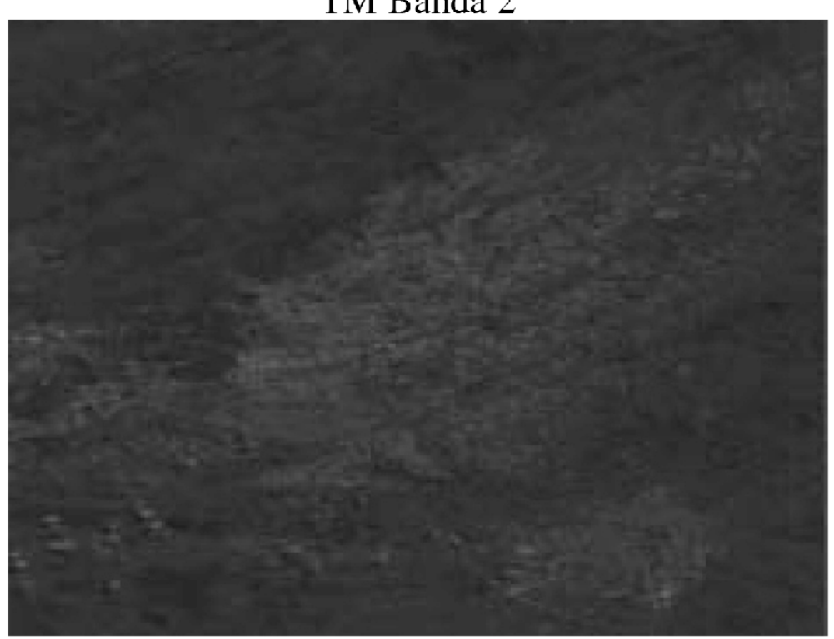

TM Banda 3

Figura 1. Imagens TM originais. 


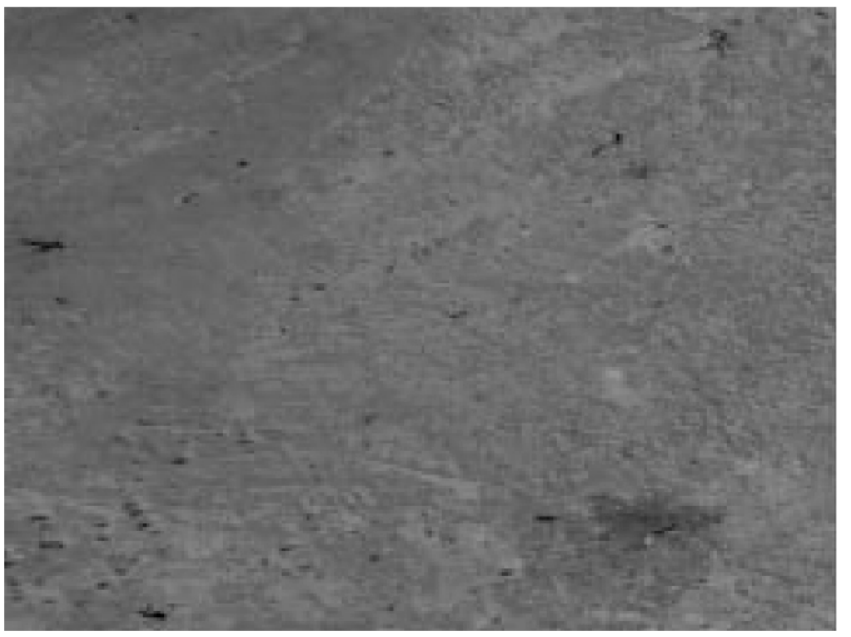

TM Banda 4

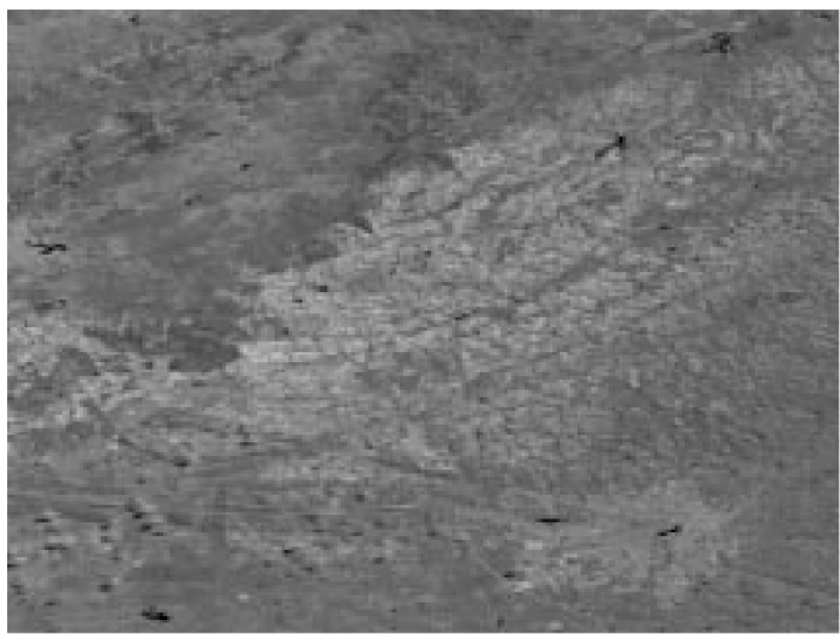

TM Banda 5

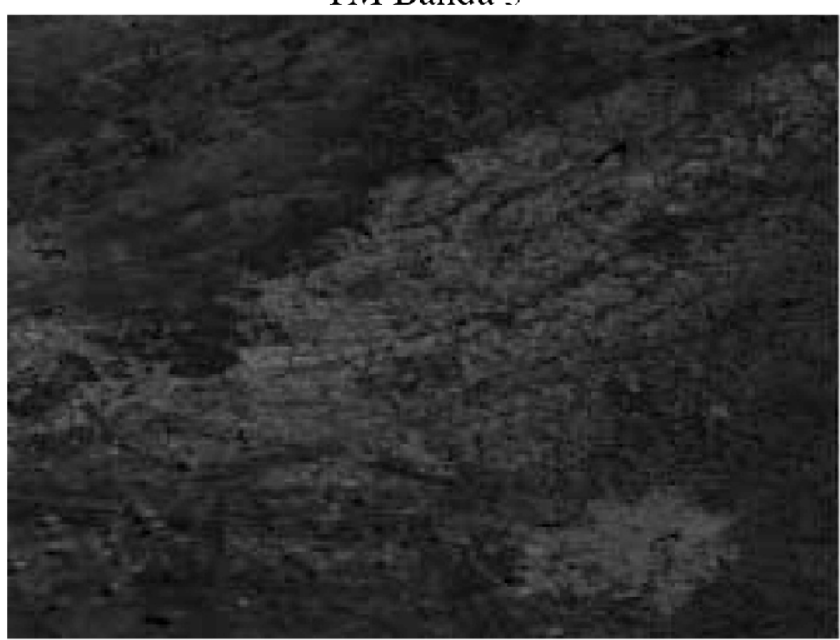

TM Banda 7

Figura 2. Imagens TM originais.

Observando-se a Figura 6, tem-se que a área de solo exposto possui alta intensidade (componente I), valores muito baixos e altos para o matiz (componente $\mathrm{H}$ ) e baixos valores de saturação (componente S). Usando-se tabelas que geram imagens binárias, é possível se separar o solo exposto dos outros alvos, sendo o primeiro mapeado para 255 e o segundo para zero. Como resultado, tem-se as Figuras 7 e 8 .

\section{Sistema Geográfico de Informações}

O objetivo deste item é gerar um mapa de drenagem para posterior inferência sobre o tipo de solo da região.

1. Inicialmente, georeferenciou-se a imagem com base na carta topográlica de Sapé, na escala 1/100.000;

2.digitalizou-se a drenagem diretamente da imagem na tela e gerou-se o mapa de drenagem;

3.estimou-se o lipo de solo seguindo as observações feilas por Frost (1960), citado em Valério Filho (1981).

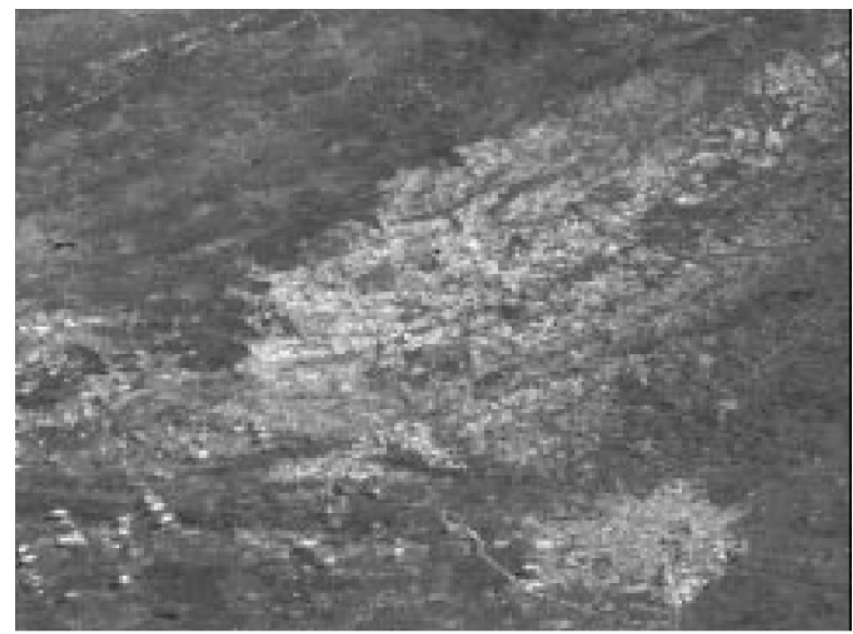

TM Banda 1

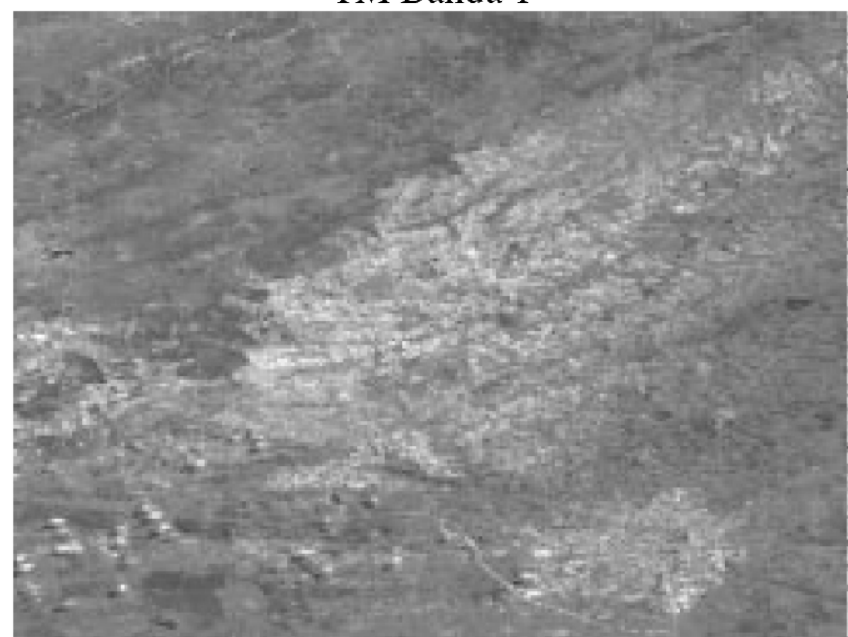

TM Banda 2

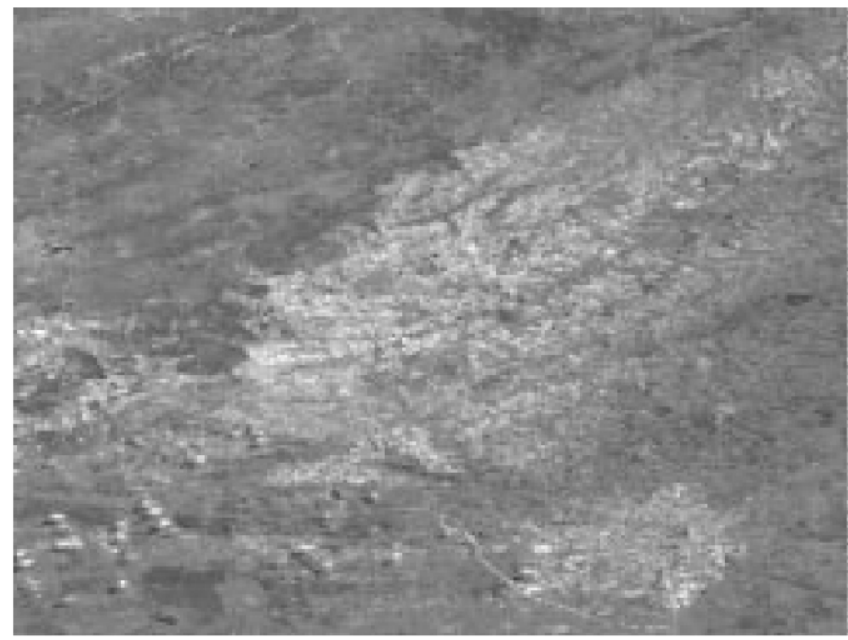

TM Banda 3

Figura 3. Imagens TM realçadas por tabela. 


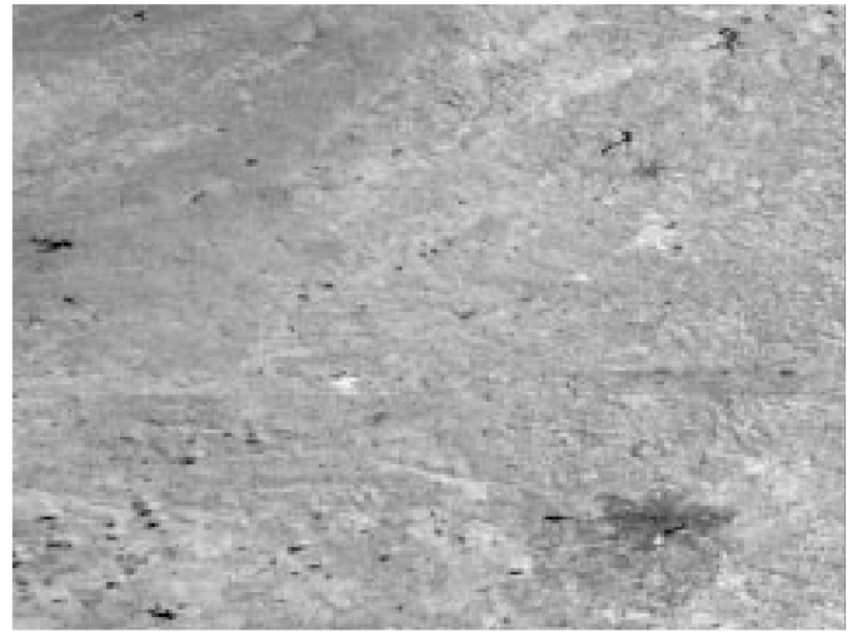

TM Banda 4

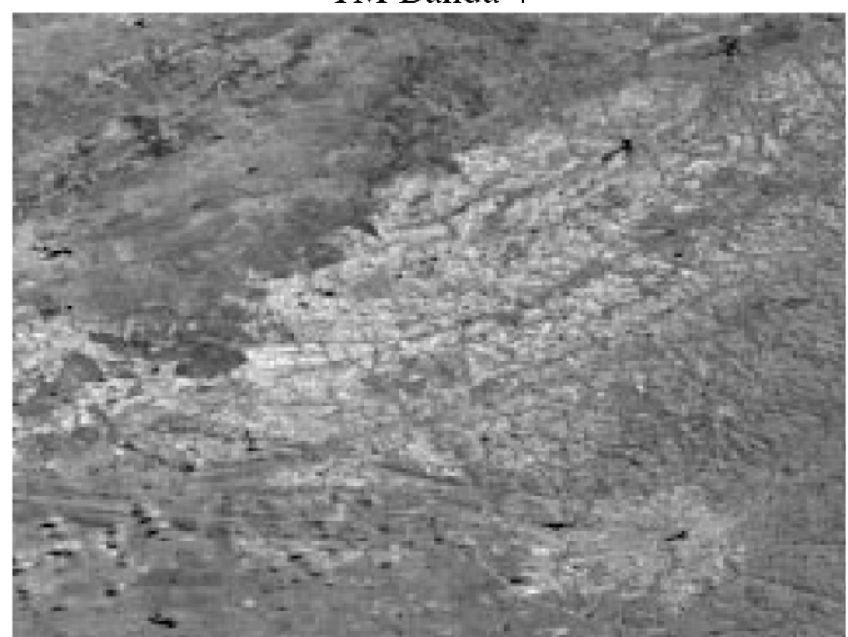

TM Banda 5

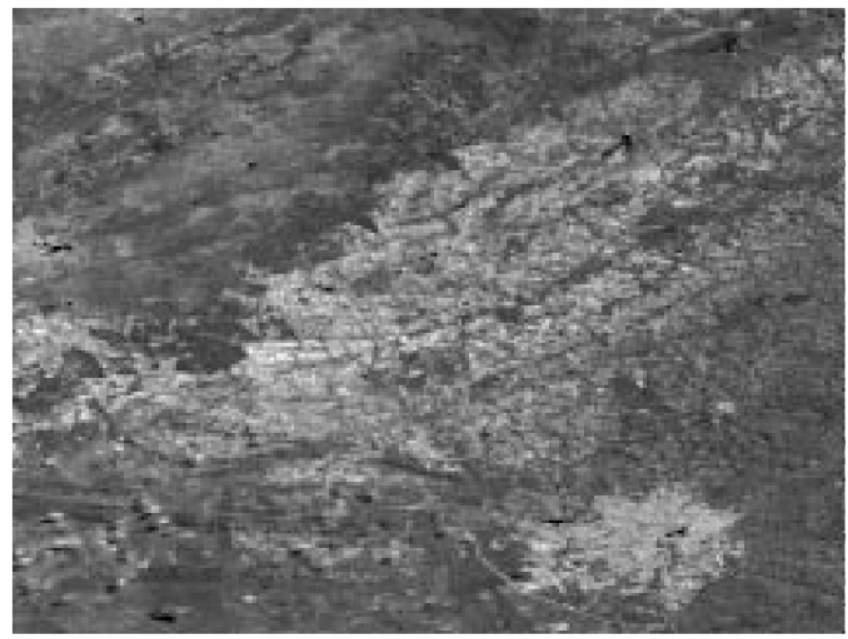

TM Banda 7

Figura 4. Imagens TM realçadas por tabela.

Segundo Sousa (1996) pode-se extrair determinada área em uma imagem, através da aplicação de uma tabela que a torne em imagem binária. Esta aplicação tem melhor efeito com uma imagem no sistema IHS, pois possui componentes independentes; assim sendo, transformou-se a imagem de interesse para o sistema IHS, aplicou-se uma tabela à componente I que enfatizasse os níveis altos de cinza; aplicou-se outra tabela à componente $\mathrm{H}$, que enfatizasse lanto níveis altos como baixos, atribuindo valor zero aos níveis de cinza intermediários e outra à componente $\mathrm{S}$ que enfatizasse a área menos saturada. Como resultado, obtevese a região de solo exposto da imagem original (Figuras 7 e 8).

Segundo Frost (1960), cilado em Valério Filho (1981) os solos podem ser classificados em fotointerpretação, pois cada feição na superfície apresenta características associadas a cada tipo de solo. Em outras palavras, por exemplo, o estudo da rede de drenagem possibilita inferir sobre a permeabilidade do substrato e, assim, sobre o possível tipo de solo. Vale salientar

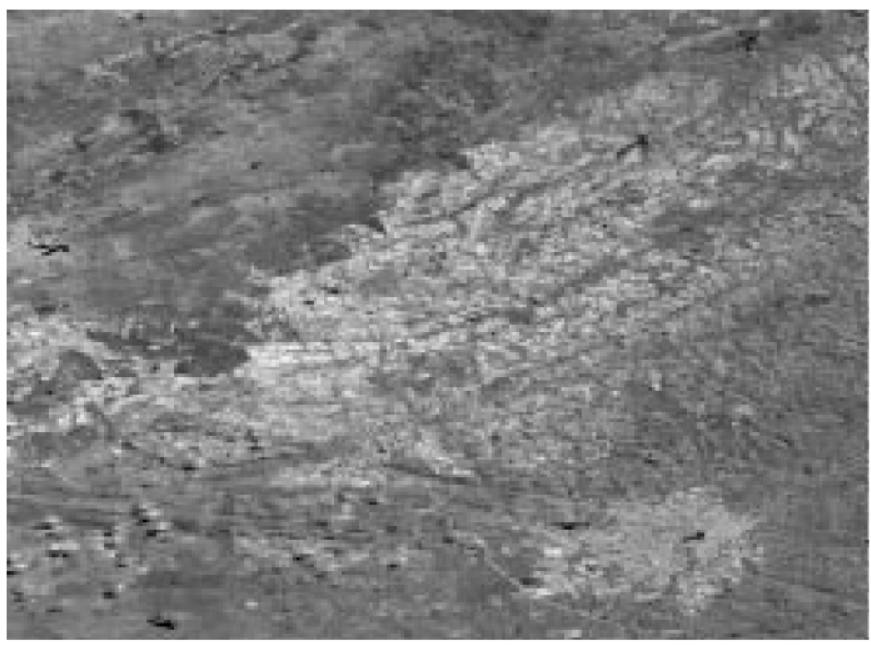

TM Bandas 752

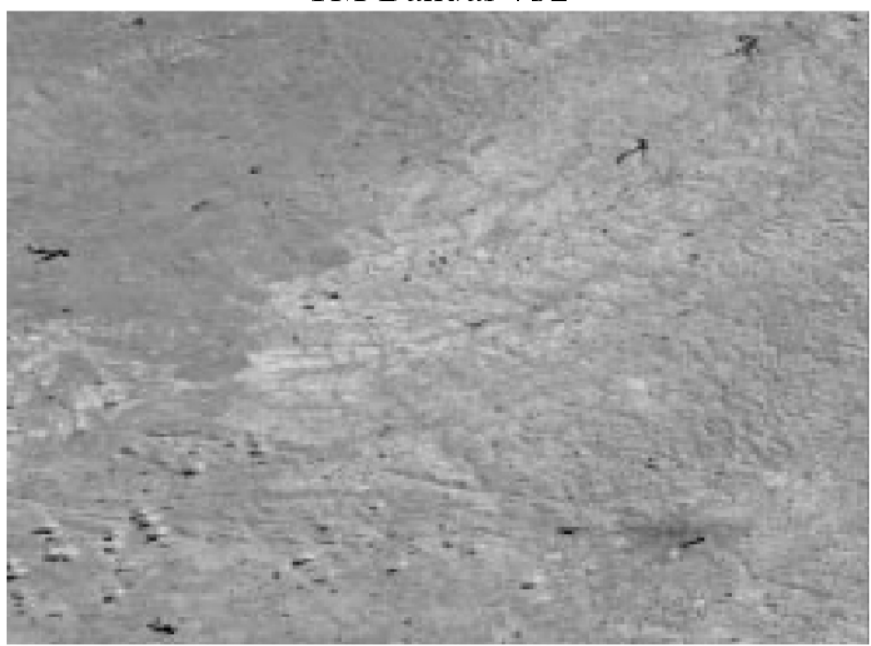

TM Bandas 543

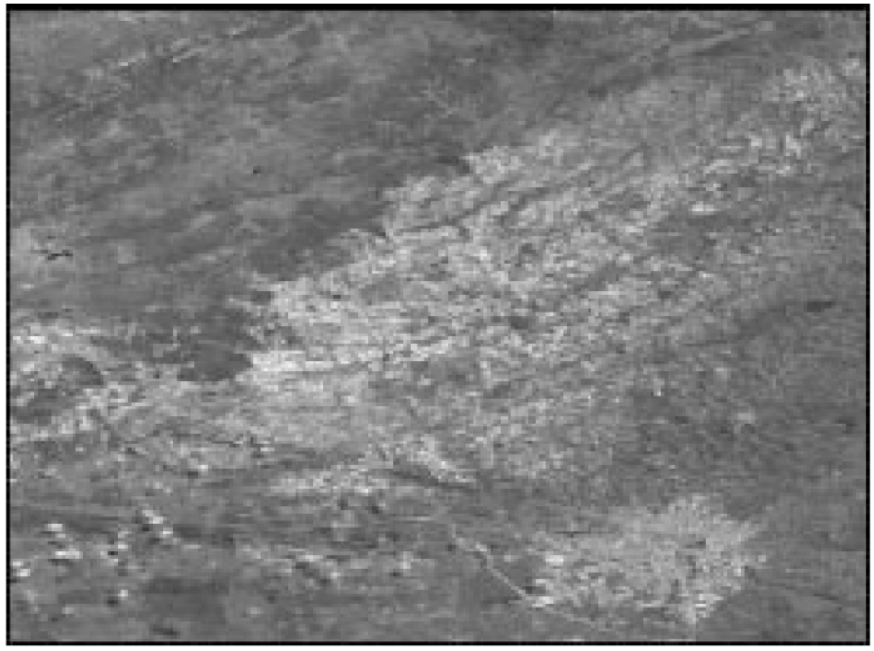

TM Bandas 721

Figura 5. Composições coloridas. 


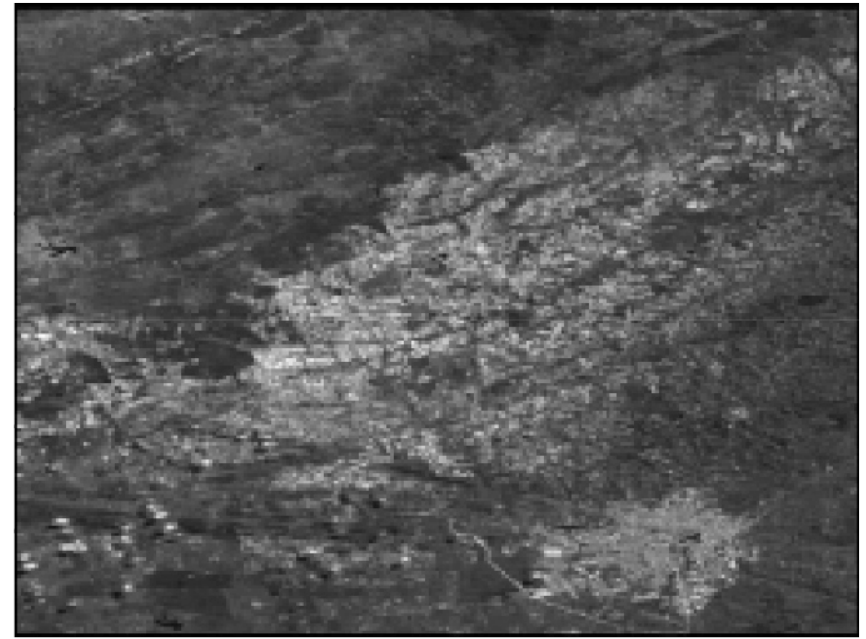

Banda I

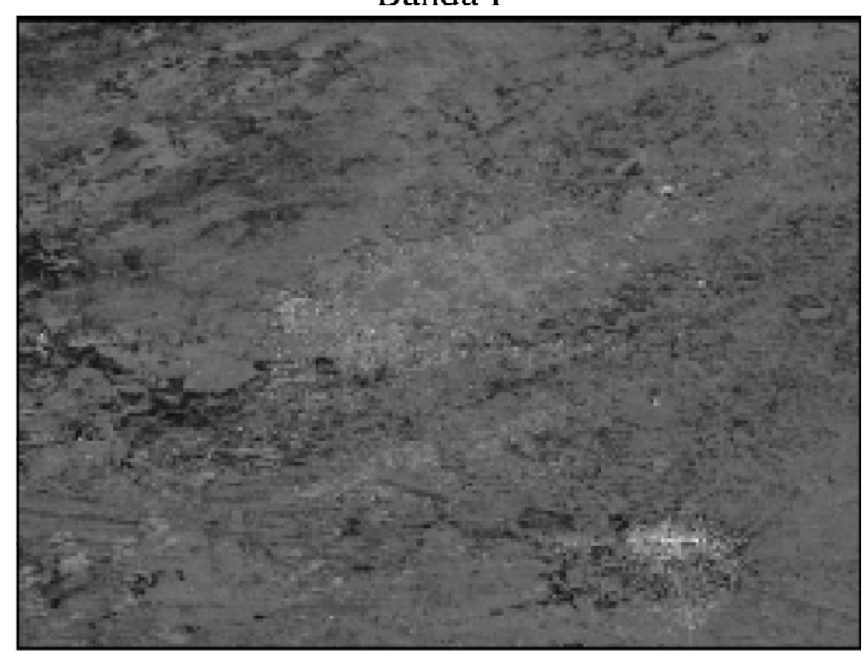

Banda $\mathrm{H}$

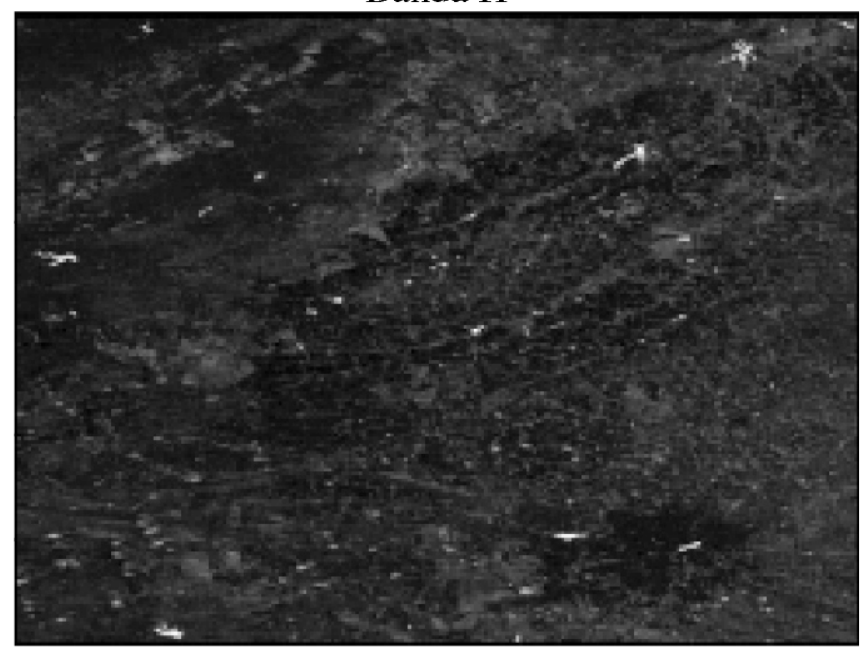

Banda S

Figura 6. Bandas IHS

que tal classificação não nos informa precisamente sobre o tipo de solo, já que as informações imageadas são da superfície.

Observando-se o padrão superficial geral da drenagem (Figura 9) vê-se que apresenta, como padrão clássico, a forma dendrílica, densidade moderada caracterizando uma região homóloga quanto à infiltração onde há predominância de lineações, como foliações, fraturamentos e acamamentos; apresenta, também, tropia multidirecional preferencial com distribuição não uniforme da rede de drenagem. Analisando-se tais características, pode-se concluir que, provavelmente a área estudada é composta de materiais facilmente erodíveis ou, então, que tenham resistência uniforme aos processos erosivos. Segundo o boletim técnico de levantamento exploratório e reconhecimento de solos do Estado da Paraíba, os tipos de solo prováveis para estas características e que estão de acordo com o Projeto RADAM Brasil, são: Regossol, Podzólico e Solos Litólicos

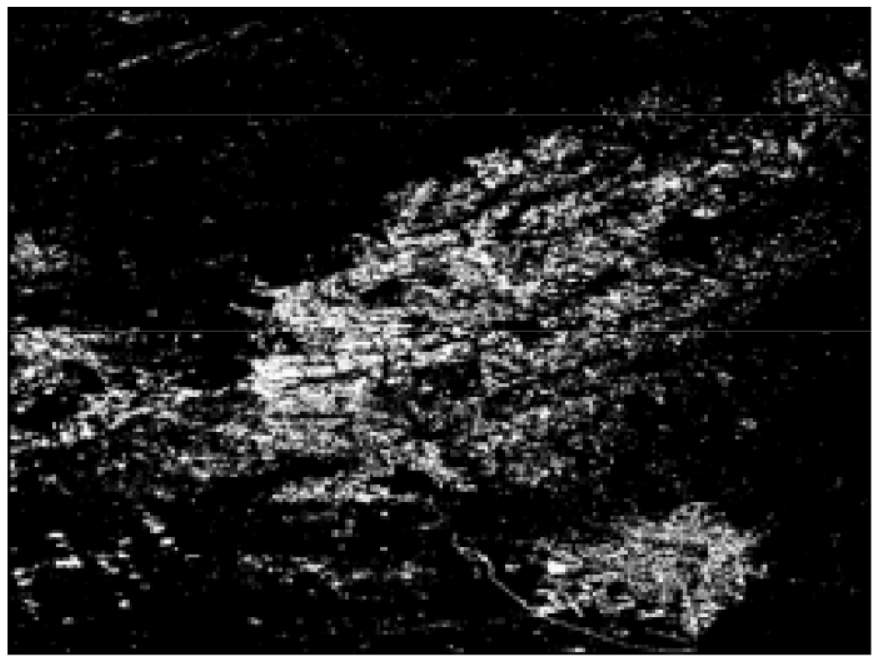

Tabela I

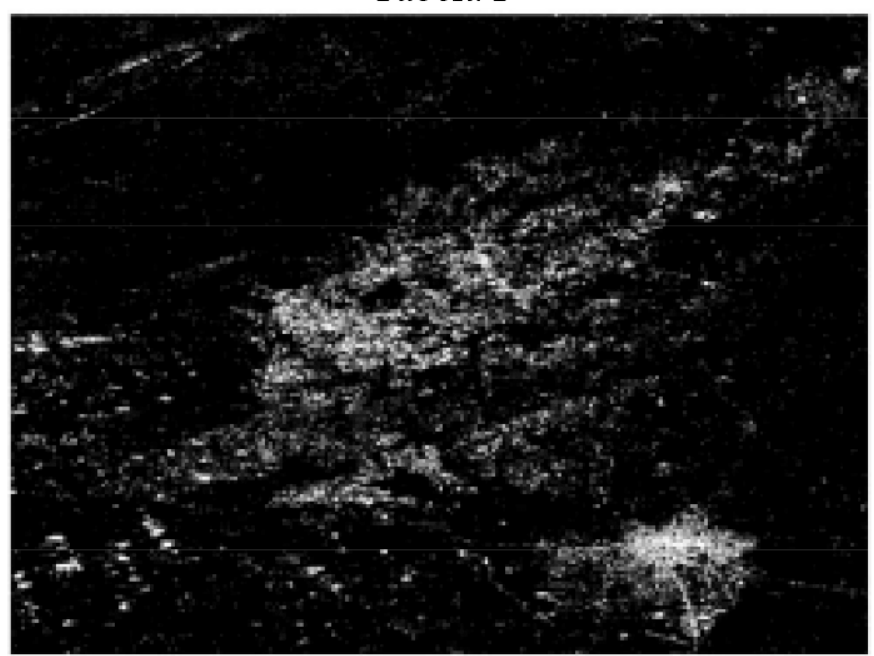

Tabela $\mathrm{H}$

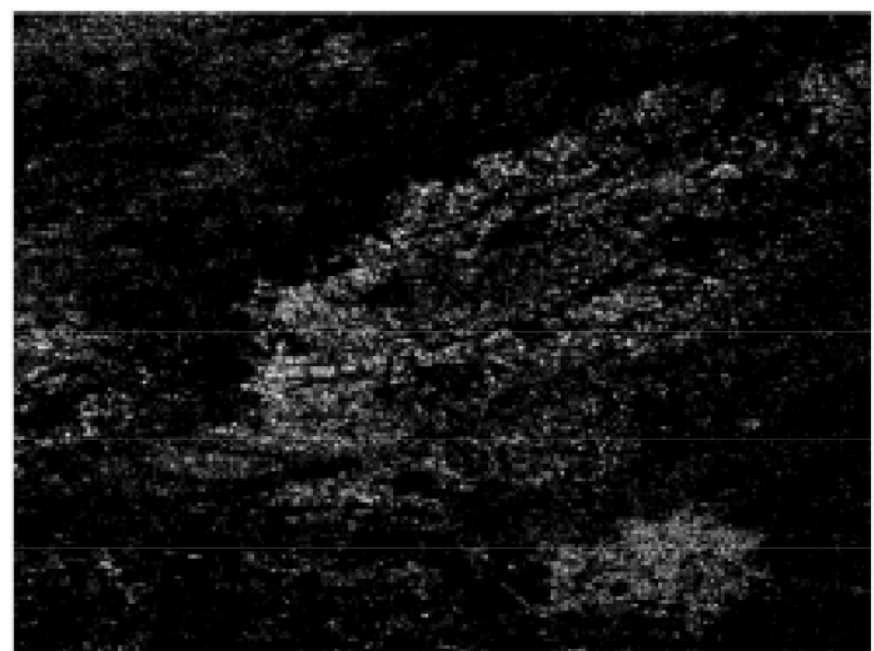

Tabela S

Figura 7. Imagens binarizadas das componentes IHS. 


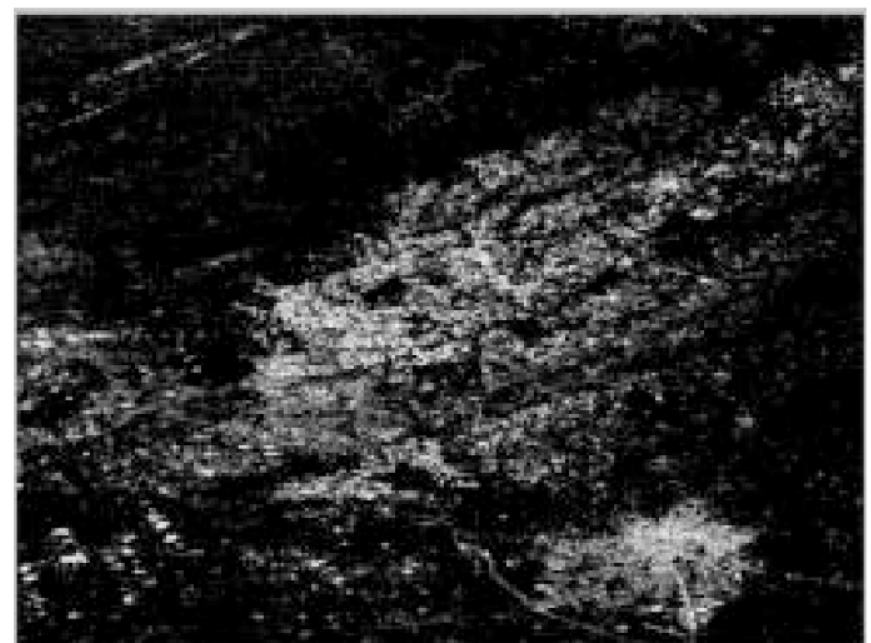

Figura 8. Composição binarizada IHS

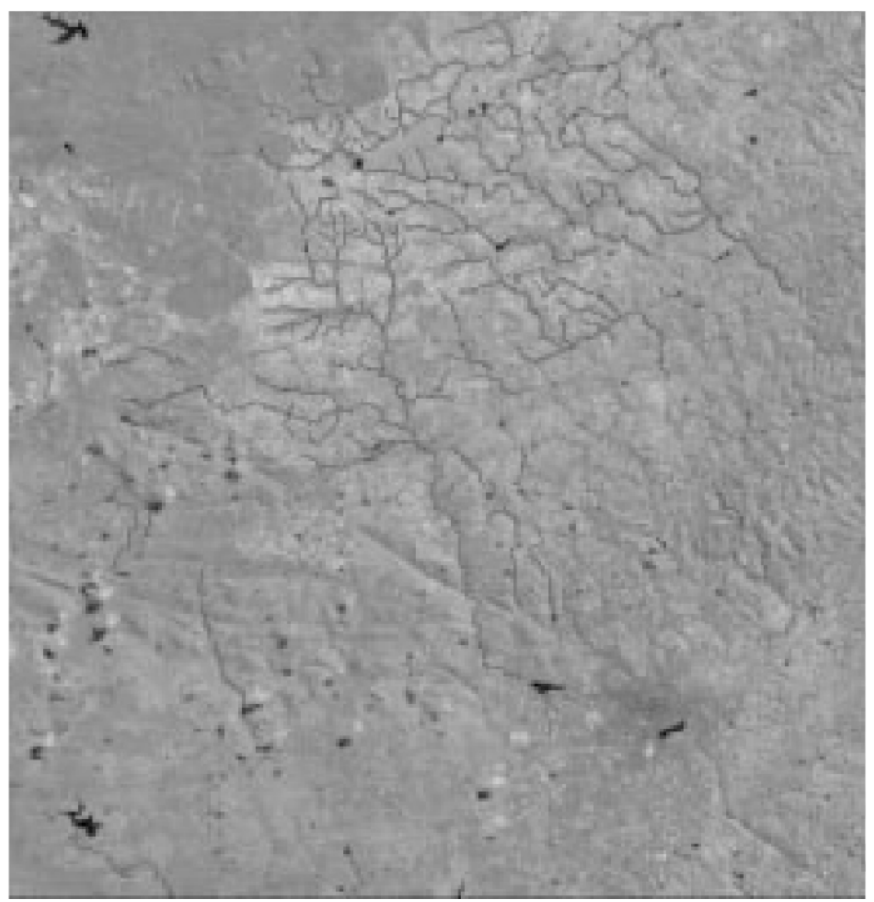

Figura 9. Drenagem para inlerência do tipo de solo

\section{CONCLUSÕES}

Este estudo foi desenvolvido em meio a grandes dificuldades; primeiro, a alta porcentagem de cobertura de nuvens na região impede a obtenção de imagens e com isto, poucos são os dados carlográficos sobre a área. Este obstáculo foi vencido utilizando-se a imagem de 19.07.1989, que apresenta baixa porcentagem de cobertura de nuvens; segundo, por não existirem dados carlográficos da área, não se tinha como georeferenciar a região. Para resolver esse problema utilizou-se a imagem completa que abrange a região de Sapé, adjacente à área de interesse, que possui carla topográfica; terceiro, para classificar o solo através de sua imagem, utilizou-se o padrão de drenagem que segundo Frost (1960), a infiltração e disposição da drenagem são função do material subsuperficial.

Desta forma, ao se classificar o solo da área através do estudo da drenagem e ao se confrontar este resultado com os dados do Projeto RADAM Brasil e com o Boletim Técnico de Levantamento Exploratório e Reconhecimento de Solos do Estado da Paraíba, vê-se que os resultados obtidos são bastante satisfatórios para as condições de realização deste trabalho.

\section{AGRADECIMENTOS}

Gostaríamos de agradecer ao LMRS (Laboratório de Meteorologia e Recursos Hídricos) que disponibilizou as máquinas para este trabalho. À professora Maria José dos Santos, que nos auxiliou na extração da drenagem e deu a idéia da inferência do solo através da drenagem, além de valiosas informações sobre a área de estudo. Ao professor Edilberto Bezerra de Sousa, por haver solucionado o problema de registro mapa/imagem com a idéia de usar um mapa adjacente à área e a cena inteira da imagem. A Miguel, pela colaboração com instruções sobre o uso dos softwares. $\mathrm{E}$ a todos aqueles que, direta ou indiretamente, colaboraram com o andamento do trabalho.

\section{REFERÊNCIAS BIBLIOGRÁFICAS}

Boletim Técnico n. ${ }^{\circ}$ 15, Levantamento ExploratórioReconhecimento de Solos do Estado da Paraíba. Convênio de Mapeamento de Solos MA/EPE-SUDENE/DRN, Convênio MA/CONTAP/USAID/BRASIL. SEDEGRA Ltda. Rio de Janeiro, 1972. 670p.

\section{BARBOSA, M.P., Sensoriamento Remoto e Sistemas de} Informação Gcográfica, Programas Espaciais, Campina Grande, PB, 1996. 34p. (3º turma Curso de Especialização).

BARBOSA, Marx Prestes, Sensoriamento Remoto c Sistemas de Informação Geográfica, Sistemas Sensores, Campina Grande, PB, 1996. 21p. (3º turma Curso de Especialização)

BARBOSA, M.P., Princípios Físicos de Sensoriamento Remoto, Campina Grande, PB, 1996. 47p. (3º lurma Curso de Especialização).

GARCIA, G.J. Sensoriamento Remoto: Princípios e Interpretação de Imagens. São Paulo: Editora Nobel, 1982. 358p.

NOVO, E.M.L. de M. Sensoriamento Remoto: Princípios e Aplicações, 2.ed. São Paulo: Editora Edgard Blücher LTDA, 1993. 308p.

UFPB. Atlas Geográfico do Estado da Paraíba, Secretaria da Educação Governo do Estado da Paraíba. João Pessoa: Grafset. 1985. 100p.

VALERIO FILHO, M., EPIPHANIO, J.C.N.; FORMAGGIO, A.R. Metodologia de interpretação de dados de sensoriamento remoto e aplicações e pedologia. São José dos Campos, INPE, Agosto, 1981 , (INPE - 2211 - MD/008). 